\title{
DOCES DE CORTE FORMULADOS COM CASCA DE MANGA ${ }^{1}$
}

\author{
Clarissa Damiani², Ana Cláudia Silva de Almeida² ${ }^{2}$ Juliana Ferreira ${ }^{2}$, \\ Eduardo Ramirez Asquieri ${ }^{3}$, Eduardo Valério de Barros Vilas Boas ${ }^{4}$, Flávio Alves da Silva ${ }^{2}$
}

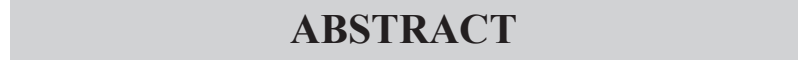

\section{SWEETS FORMULATED WITH MANGO SKIN}

Concerning the mango industrial processing, skin is a disposal component. However, it can be used as a nutrient source in many by-products. The objective of this study was to evaluate the quality of sweets formulated with $0 \%$ (control), $25 \%, 50 \%, 75 \%$, and $100 \%$ of mango skin in substitution to the mango (Mangifera indica L. cv. Haden) pulp. The quality features evaluated were: moisture, ashes, proteins, lipids, total carbohydrates, total sugars, reducing and non-reducing sugars, $\mathrm{pH}$, total acidity, titratable and citric acid acidity, total soluble solids, fibers (total, soluble, and insoluble), antioxidants, microbiological features, and sensorial acceptability (appearance, aroma, flavor, and color). For the sweets formulated with mango skin, significantly higher levels of minerals (ashes), $\mathrm{pH}$, dietary fiber, soluble solids, and sucrose were observed. Furthermore, the increase of mango skin in the formulations also increased the antioxidant activity, what suggests that the mango skin is an alternative source of natural antioxidants. The microbiological analyses results were satisfactory for all treatments, according to established standards. For the sensorial aspect, there was a good consumer acceptance, with notes above 7, for aspect, flavor, color, and aroma. Therefore, the partial or total substitution of the mango pulp by mango skin, for the formulation of Haden mango sweet is a viable alternative, when considered its nutritional, sensorial, and microbiological aspects.

KEY-WORDS: Mangifera indica L.; by-products; chemical composition.

\section{INTRODUÇÃO}

A manga é uma fruta bastante apreciada pelos consumidores brasileiros, sendo destinada ao consumo direto e/ou industrialização, na forma de compotas, geleias, sorvetes, néctares, polpas congeladas e sucos concentrados, que podem ser reconstituídos e adoçados, antes do consumo.

\section{RESUMO}

$\mathrm{Na}$ industrialização da manga, a casca é um dos componentes de descarte. No entanto, a mesma pode ser utilizada como fonte de nutrientes, na composição de diversos outros produtos. Logo, este estudo teve como objetivo avaliar a qualidade de doces de corte, formulados com $0 \%$ (controle), $25 \%, 50 \%, 75 \%$ e $100 \%$ de cascas, em substituição à polpa de manga (Mangifera indica L. cv. Haden). Os critérios de qualidade utilizados foram: umidade, cinzas, proteínas, lipídios, carboidratos totais, açúcares totais, açúcares redutores, açúcares não redutores, $\mathrm{pH}$, acidez total, acidez titulável e em ácido cítrico, sólidos solúveis totais, fibras (totais, solúveis e insolúveis), antioxidantes, características microbiológicas e aceitabilidade sensorial (aparência, aroma, sabor e cor). Nos doces formulados com casca de manga, foram observados teores significativamente maiores de minerais (cinzas), pH, fibra alimentar, sólidos solúveis e sacarose. O incremento de casca de manga, nas formulações, elevou a atividade antioxidante, permitindo sugerir que a casca da manga é uma fonte alternativa de antioxidantes naturais. Os resultados das análises microbiológicas foram satisfatórios para todos os tratamentos, estando dentro dos padrões estabelecidos. No aspecto sensorial, houve boa aceitação, com notas acima de 7, para aparência, sabor, cor e aroma. Portanto, a substituição parcial ou total da polpa por cascas, na formulação de doce de corte de manga Haden é uma alternativa viável, sob os aspectos nutricional, sensorial e microbiológico.

PALAVRAS-CHAVES: Mangifera indica L.; subprodutos; composição química.

Durante o processamento da manga, a casca e a semente são descartadas, gerando $40-50 \%$ da massa total da fruta em rejeitos (FAO 2009) que poderiam ser aproveitados como fonte alternativa de nutrientes.

O aproveitamento de cascas, talos e outros componentes descartados pela agroindústria mostra-se uma boa alternativa para o combate à fome, à miséria e ao desperdício, promovendo a segurança

1. Trabalho recebido em maio/2010 e aceito para publicação em ago./2011 (n registro: PAT 9815/ DOI: 10.5216/pat.v41i3.9815).

2. Universidade Federal de Goiás, Escola de Agronomia e Engenharia de Alimentos, Goiânia, GO, Brasil.

E-mails: damianiclarissa@hotmail.com, flaviocamp@gmail.com,nanas580@hotmail.com,ju_ferreirams@hotmail.com.

3. Universidade Federal de Goiás, Faculdade de Farmácia, Goiânia, GO, Brasil. E-mail: asquieri@gmail.com.

4. Universidade Federal de Lavras, Departamento de Ciência de Alimentos, Lavras, MG, Brasil.E-mail: evbvboas@ufla.br. 
alimentar, por meio de uma educação para o consumo, de forma consciente.

Com o propósito de minimizar o desperdício e oferecer uma opção de alimentação alternativa de baixo custo, Oliveira et al. (2002) estudaram o aproveitamento da casca do maracujá-amarelo (Passiflora edulis f. Flavicarpa), a qual tem como constituintes básicos carboidratos, proteínas e pectina, aproveitáveis como matéria-prima para a elaboração de doce em calda. Verificaram boa aceitação, principalmente por parte de crianças, além de favorecer a geração de renda para empreendedores, com o aumento do valor comercial para o produto, diminuindo o desperdício das partes não convencionais para consumo.

Em razão de a manga ser uma fruta sazonal e muito abundante, em vários países tropicais, seria vantajoso, tanto em termos econômicos como nutricionais, tornar viável um melhor aproveitamento da mesma, de maneira que possam ser preservados, tanto quanto possível, seus componentes naturais, como vitaminas, pigmentos, fibras, açúcares e outros.

Neste sentido, a industrialização da manga, inclusive da casca, pode ser uma alternativa para atenuar perdas, pelo aproveitamento das frutas fora do padrão de comercialização in natura, para abrandar a geração de resíduos orgânicos sólidos e produzir alimentos saudáveis, pela incorporação de fibras e compostos com atividade antioxidante. Profissionais de saúde têm recomendado maior ingestão de fibras alimentares, incentivando o consumo de frutas e hortaliças, como forma de se reduzir a incidência de doenças crônico-degenerativas. Por outro lado, a busca por substitutos naturais para os antioxidantes sintéticos tem elevado o número de pesquisas envolvendo alimentos de origem vegetal que são potenciais fontes destas substâncias (Kaur \& Kapoor 2002, Wolfe 2003, Oliveira et al. 2007).

Logo, o objetivo do presente estudo foi desenvolver doces de corte, formulados com diferentes níveis de casca da manga cv. Haden, em substituição à polpa, avaliando-se as características químicas, sensoriais e microbiológicas dos produtos finais.

\section{MATERIAL E MÉTODOS}

O experimento foi conduzido no Laboratório de Química e Bioquímica de Alimentos da Faculdade de Farmácia da Universidade Federal de Goiás (UFG), em Goiânia (GO).
Avaliaram-se diferentes níveis de casca $(0 \%$, $25 \%, 50 \%, 75 \%$ e $100 \%)$, em substituição à polpa, no doce de corte de manga, e suas características químicas, sensoriais e microbiológicas. O delineamento utilizado foi o inteiramente casualizado (DIC) simples, com três repetições para cada tratamento, sendo cada unidade experimental constituída de uma embalagem contendo, aproximadamente, $25 \mathrm{~g}$ do produto. Foi avaliada a influência de cinco níveis de casca, na formulação dos doces de corte.

As mangas (variedade Haden) utilizadas para elaboração do doce foram adquiridas no mercado local de Goiânia, em abril de 2009, provenientes da Fazenda Santana, região do Vale do Rio São Francisco, onde foram colhidas no início do mês de abril de 2009. Os frutos encontravam-se selecionados, embalados em caixas de papelão e mantidos sob refrigeração. Quanto aos estádios de maturação, estes se apresentavam heterogêneos, ou seja, alguns no início do amadurecimento e outros já maduros.

Os frutos foram levados ao Laboratório de Química e Bioquímica de Alimentos da Faculdade de Farmácia da UFG, onde foram higienizados, descascados e despolpados, e os doces processados. A polpa das mangas foi triturada em liquidificador industrial e as cascas cozidas em água potável, por 40 minutos $\left(100 \pm 2^{\circ} \mathrm{C}\right)$, em panelas de alumínio. Após esta etapa, as cascas foram trituradas com a própria água do cozimento e refinadas em despolpadeira. Em seguida, foram verificados o $\mathrm{pH}$ e a acidez titulável do suco da polpa e da casca, com a finalidade de quantificar o teor de ácido cítrico a ser incorporado à formulação dos doces.

As formulações dos doces de corte de manga, com diferentes níveis de cascas $(0 \%, 25 \%, 50 \%$, $75 \%$ e 100\%), em substituição à polpa, encontram-se detalhadas na Tabela 1.

Tabela 1. Ingredientes utilizados na formulação de doces de corte de manga com diferentes níveis de cascas, em substituição à polpa (Goiânia, GO, 2009).

\begin{tabular}{crrrrc}
\hline \multirow{5}{*}{$\begin{array}{c}\text { Níveis de } \\
\text { substituição de } \\
\text { casca (\%) }\end{array}$} & \begin{tabular}{c} 
Ingredientes (g) \\
\cline { 2 - 6 } manga
\end{tabular} & $\begin{array}{c}\text { Polpa de } \\
\text { manga }\end{array}$ & Açúcar & Pectina & $\begin{array}{c}\text { Ácido } \\
\text { cítrico }\end{array}$ \\
\hline 0 (controle) & 0 & 3000 & 1800 & 60 & 24 \\
25 & 750 & 2250 & 2000 & 30 & 24 \\
50 & 1500 & 1500 & 2000 & 30 & 24 \\
75 & 2250 & 750 & 2000 & 30 & 18 \\
100 & 3000 & 0 & 3000 & - & 18 \\
\hline
\end{tabular}


Para a produção do doce, misturou-se um terço do açúcar com a solução homogênea de suco de polpa e casca, e levou-se a mistura para o concentrador, onde a mesma permaneceu até o início da ebulição, momento no qual adicionou-se mais um terço do açúcar, previamente homogeneizado com a pectina. Após nova ebulição, acrescentou-se o restante do açúcar e esperou-se até que a concentração alcançasse $63^{\circ}$ Brix. Neste instante, adicionou-se o ácido cítrico, diluído em água potável, para a redução do $\mathrm{pH}$, até, aproximadamente, 3,2 , e concentrou-se até $75^{\circ}$ Brix. Após esta etapa, o doce, ainda quente, foi depositado em vasilhas de alumínio, previamente esterilizadas e forradas com papel manteiga. Deixou-se esfriar, até que o mesmo estivesse no ponto ideal de corte (sob refrigeração). Logo após, fez-se o corte em cubos de, aproximadamente, $25 \mathrm{~g}$ cada, os quais foram passados em açúcar cristal, embalados em plástico de polietileno de baixa densidade (PEBD) e, em seguida, etiquetados.

Foram feitas análises centesimais e químicas nos doces obtidos em todos os tratamentos, logo após o processamento, em triplicata, sendo que cada unidade amostral foi constituída de $25 \mathrm{~g}$. As análises de umidade, cinzas, proteínas, lipídios, $\mathrm{pH}$, acidez titulável total, sólidos solúveis, açúcares e potencial antioxidante foram realizadas no Laboratório de Química e Bioquímica de Alimentos da UFG e as análises de fibras no Laboratório de Análise, Pesquisa e Consultoria (LABM), em Belo Horizonte (MG).

Os teores de umidade, cinzas, proteínas, fibras (total, insolúvel e solúvel), açúcares totais, açúcares redutores e acidez titulável foram determinados segundo Brasil (2005); os lipídios conforme Bligh \& Dyer (1959); o pH e os sólidos solúveis totais de acordo com a AOAC (1997); os carboidratos totais conforme Dubois et al. (1956); o valor calórico total foi estimado segundo os valores de conversão de Atwater, descritos por Wilson et al. (1982), em triplicata; e o potencial antioxidante de acordo o método descrito por Brand-Williams et al. (1995), modificado por Borguini \& Torres (2009), também em triplicata.

As análises microbiológicas foram realizadas nos diferentes tratamentos, logo após o processamento, segundo as metodologias propostas por Silva et al. (2007), no Laboratório de Microbiologia do Instituto de Fosfatos Biológicos (IFB), em Goiânia (GO). Em triplicata, amostras de $25 \mathrm{~g}$ de cada tratamento (controle, 25\%, 50\%, 75\% e 100\% de casca, em substituição à polpa) foram retiradas, aleatoriamente, de cada lote e, em seguida, homogeneizadas com
$225 \mathrm{~mL}$ de água peptonada a $0,1 \%(\mathrm{p} / \mathrm{v})$ esterilizada, em liquidificador doméstico, durante um minuto, com copo previamente sanificado com etanol (70\%). Analisou-se o número mais provável por grama de amostra (NMP g ${ }^{-1}$ ) de coliformes a $35^{\circ} \mathrm{C}$ e a $45^{\circ} \mathrm{C}$, a presença ou ausência de Salmonella e o número de unidades formadoras de colônias (UFC) de bolores e leveduras.

O teste de aceitação, em escala hedônica de 9 pontos (um - desgostei muitíssimo até nove - gostei muitíssimo), foi realizado com 100 julgadores não treinados, entre crianças, adultos e idosos de ambos os sexos, para avaliação da aparência, aroma, sabor e da cor das cincos formulações de doce de corte, conforme Della Modesta (1994). As análises de visualização e degustação dos doces foram realizadas logo após o processamento, em supermercado da cidade de Goiânia, e os avaliadores foram recrutados aleatoriamente, dentro deste estabelecimento. Foram oferecidas amostras de $25 \mathrm{~g}$ e $50 \mathrm{~mL}$ de água, entre cada tratamento avaliado.

Os resultados das respostas analisadas foram submetidos a análise de variância e, quando significativas $(\mathrm{p} \leq 0,05)$, estas foram submetidas a análises de regressão polinomial.

\section{RESULTADOS E DISCUSSÃO}

Os tratamentos apresentaram os seguintes

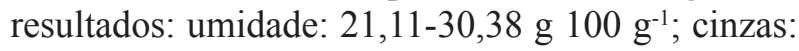
0,187-0,357 g $100 \mathrm{~g}^{-1}$; proteínas: 1,05-1,57 g $100 \mathrm{~g}^{-1}$; lipídios: $0,116-0,283 \mathrm{~g} 100 \mathrm{~g}^{-1}$; carboidratos totais: 67,69-76,15 g $100 \mathrm{~g} \mathrm{~g}^{-1}$; e valor calórico: 278,37-313 kcal (Figura 1). Com relação à umidade, verificou-se que quanto maior a substituição de cascas por polpa de manga, maior o teor de umidade encontrado no doce (Figura 1). Isto pode ser explicado com base na própria formulação, pois, durante o preparo do suco da casca de manga, houve incorporação de água, para facilitar a trituração.

Verificou-se que, com a incorporação de casca na formulação, houve, também, aumento no teor de cinzas. Conforme estudos realizados por Damiani et al. (2009), o teor de cinzas encontrado na casca

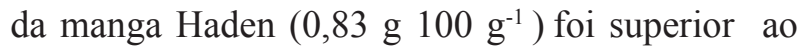

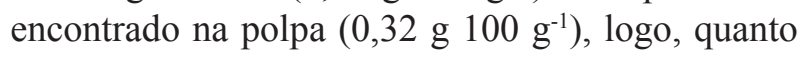
maior a percentagem de casca na formulação, maior o teor de cinzas.

Em relação ao teor de proteína, observou-se uma diminuição, seguida de ascensão da curva 

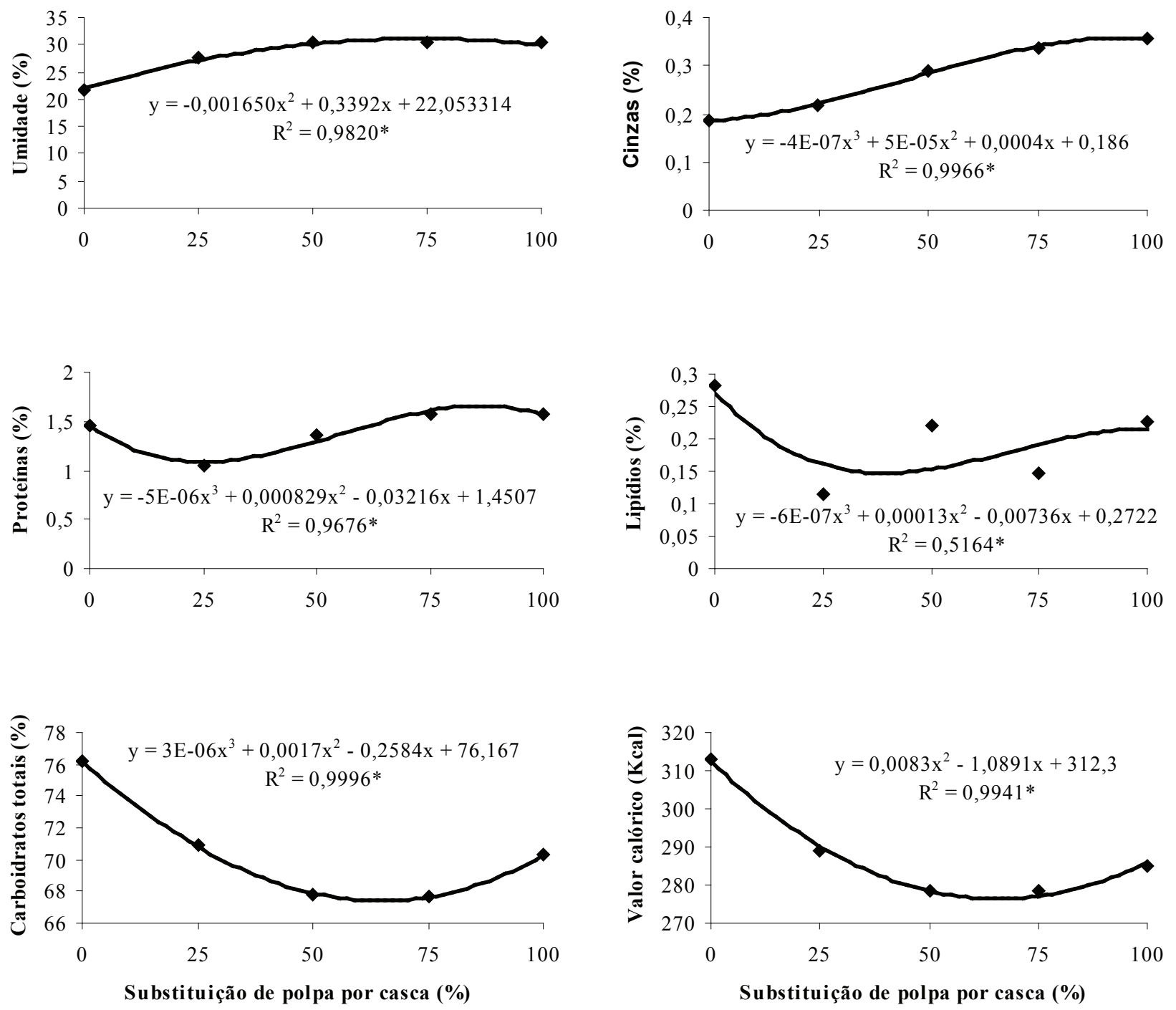

Figura 1. Composição centesimal (\%) e valor calórico (kcal) dos doces de manga, em função do nível de substituição da polpa por casca (Goiânia, GO, 2009). * $\mathrm{p} \leq 0,05$.

(Figura 1), evidenciando que quanto maior o teor de casca no doce, maior a quantidade de proteínas, exceto para a formulação com $25 \%$ de casca. Este fato pode ter ocorrido devido a este tratamento ter sofrido maior tempo de cocção para atingir $75^{\circ}$ Brix, ficando, portanto, mais exposto às altas temperaturas, podendo ter ocorrido desnaturação das proteínas presentes, resultando em baixo teor das mesmas.

O teor de lipídios variou entre os tratamentos, o que poderia ser explicado pela desuniformidade do estádio de maturação em que as frutas encontravam-se (algumas mais maduras que outras). Como as mangas utilizadas neste experimento foram procedentes da Região Nordeste, as mesmas foram colhidas e embaladas ainda maturas, porém não maduras, logo, por serem climatéricas, da colheita até a comercialização, estas amadurecem, porém, não uniformemente. Logo, o amadurecimento heterogêneo, durante o transporte e a comercialização, pode ter contribuído com esta diferença no teor de lipídios.

O conteúdo de carboidratos totais e valor calórico apresentaram a mesma tendência de declínio, com a incorporação das cascas na formulação do doce, quando comparado ao tratamento controle. $\mathrm{O}$ valor calórico decresceu com a incorporação de até $75 \%$ de casca (de $313 \mathrm{kcal}$ para $278,37 \mathrm{kcal}$ ), seguido de ascensão no tratamento com $100 \%$ de casca $(285,24$ kcal) (Figura 1).

Verificou-se que os valores de sólidos solúveis (Figura 2) variaram $69,67-77,67^{\circ}$ Brix, nos diferen- 
tes produtos, e estão de acordo com o estabelecido pela legislação brasileira, para doce de corte, que preconiza um mínimo de $65 \%$ de sólidos solúveis no produto final (Brasil 1978). Os sólidos solúveis totais compreendem, fundamentalmente, os açúcares (redutores e não redutores) e os ácidos orgânicos (Silva et al. 2005). O aumento dos teores de sólidos solúveis afetou a textura do doce de duas maneiras: por um lado, a redução do teor de água aumentou a rigidez da estrutura e, por outro, a necessidade de se evaporar uma maior quantidade da água da massa acarretou, necessariamente, aumento no tempo de cozimento e na temperatura da massa. Com isto, aumentaram-se as chances de hidrólise da pectina, o que torna a estrutura mais contínua e aderente (Soares Júnior et al. 2003).

Os valores de $\mathrm{pH}$ encontrados nas diferentes formulações variaram de 3,55 a 3,76. Nascimento et al. (2003) encontraram $\mathrm{pH}$ de 3,5, para o doce de casca de maracujá amarelo, valor, este, muito próximo aos encontrados no doce de corte com diferentes teores de casca, em substituição à polpa de manga.

Verificou-se que a acidez total variou 1,031,17\% (Figura 2). $\mathrm{O}$ fato de ter sido utilizado ácido cítrico na formulação influenciou diretamente os valores de acidez total encontrados.
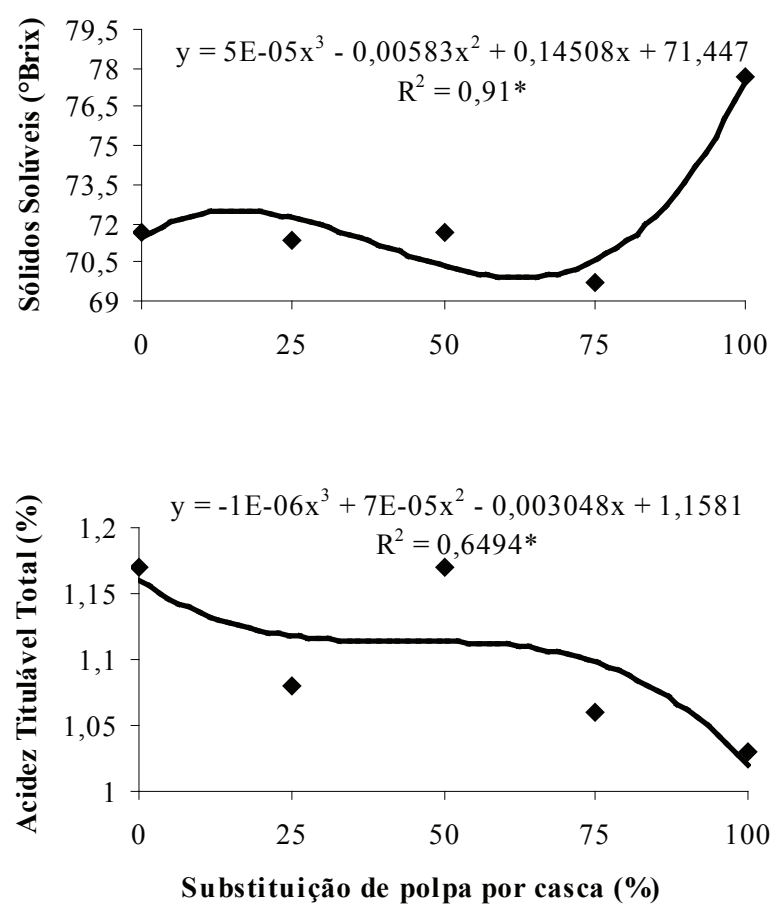

Em relação à acidez titulável em ácido cítrico, verificou-se que esta variou 0,64-0,77 g $100 \mathrm{~g}^{-1}$. Segundo Damiani et al. (2009), a acidez titulável

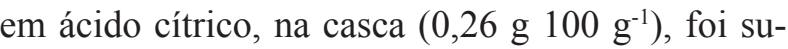
perior à encontrada na polpa da manga $\mathrm{cv}$. Haden

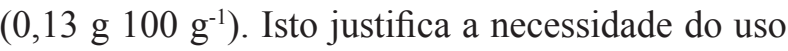
de uma maior quantidade de ácido cítrico nas formulações com maior teor de polpa de manga, conforme ilustrado na Tabela 1.

Pôde-se observar que os valores de açúcares totais variaram $60-71,53 \%$ (Figura 3 ). Esta pequena variação pode ser explicada pela relação entre a quantidade de polpa de manga utilizada na formulação e a quantidade de açúcares totais contida nesta mesma polpa, a qual foi superior à da casca, conforme dados encontrados por Damiani et al. (2009), ao analisarem a polpa e a casca da manga cv. Haden $\left(13,20{\mathrm{~g} 100 \mathrm{~g}^{-1}}^{-1}\right.$

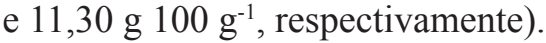

Analisando-se os açúcares redutores e não redutores, verificou-se que a quantidade de açúcares não redutores predominou sobre os redutores, ou seja, o doce contém, principalmente, sacarose.

Em relação à quantidade de fibra total ou fibra bruta, nos diferentes tratamentos formulados (Figura 4), notou-se que, conforme aumentou o teor de casca na formulação, aumentou, também,
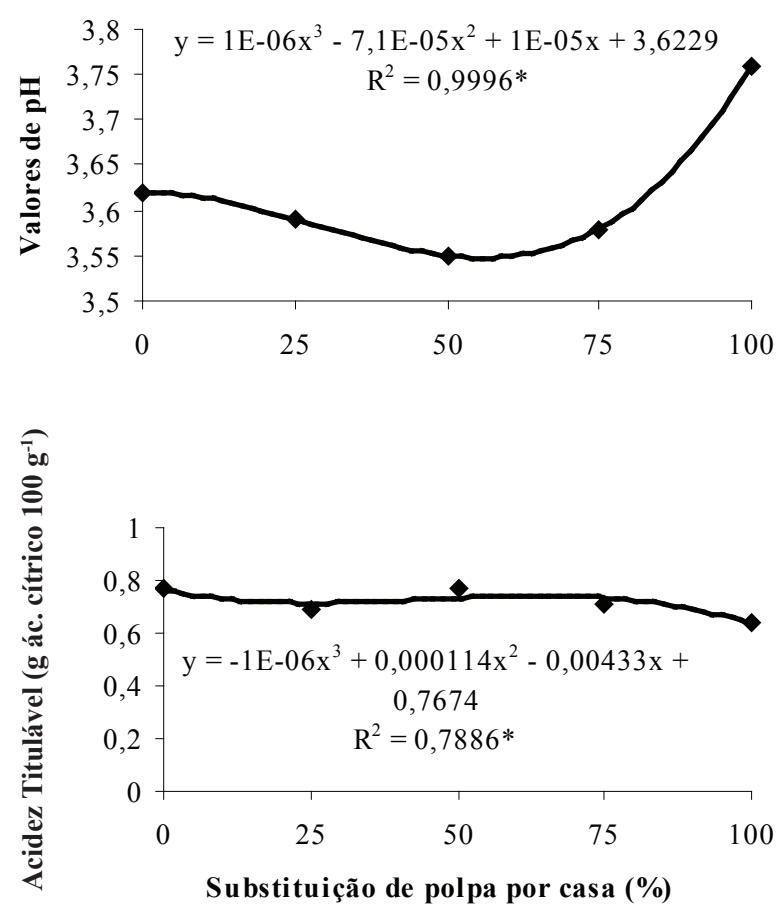

Figura 2. Composição química (\%) dos tratamentos com diferentes níveis de cascas de manga, em substituição à polpa, na fabricação de doce de corte (Goiânia, GO, 2009). * $\mathrm{p} \leq 0,05$. 


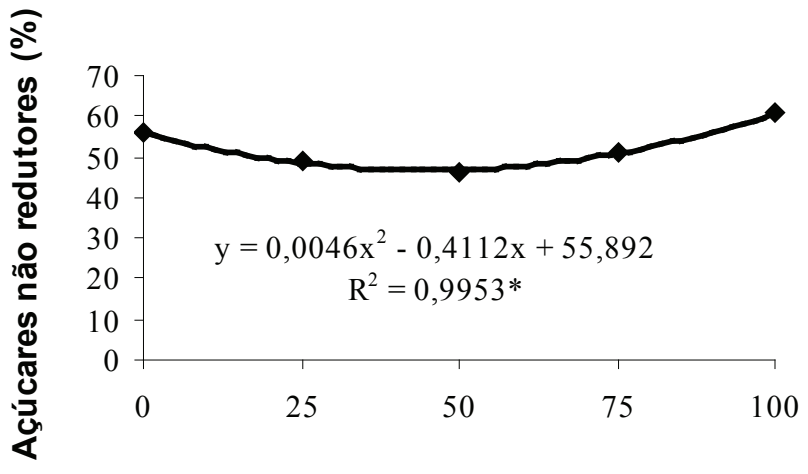

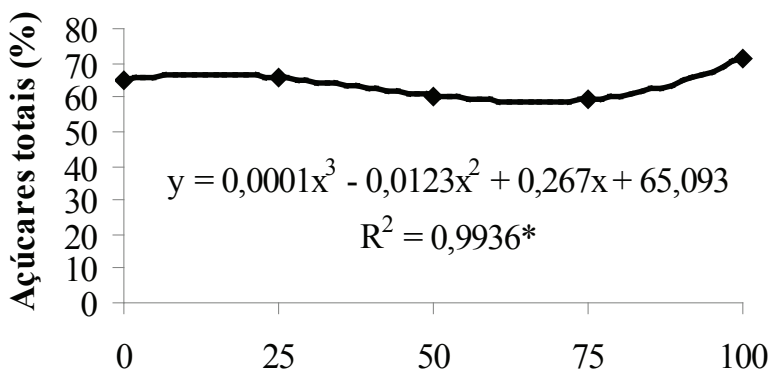

Substituição de polpa por casca (\%)

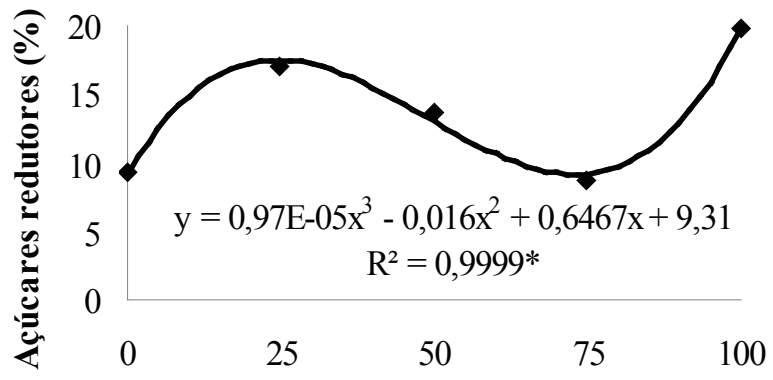

Subs tituição de polpa por casca (\%)

Figura 3. Quantidade de açúcares totais, redutores e não redutores dos tratamentos com diferentes níveis de cascas de manga, em substituição à polpa, na fabricação de doce de corte (Goiânia, GO, 2009). * p $\leq 0,05$.
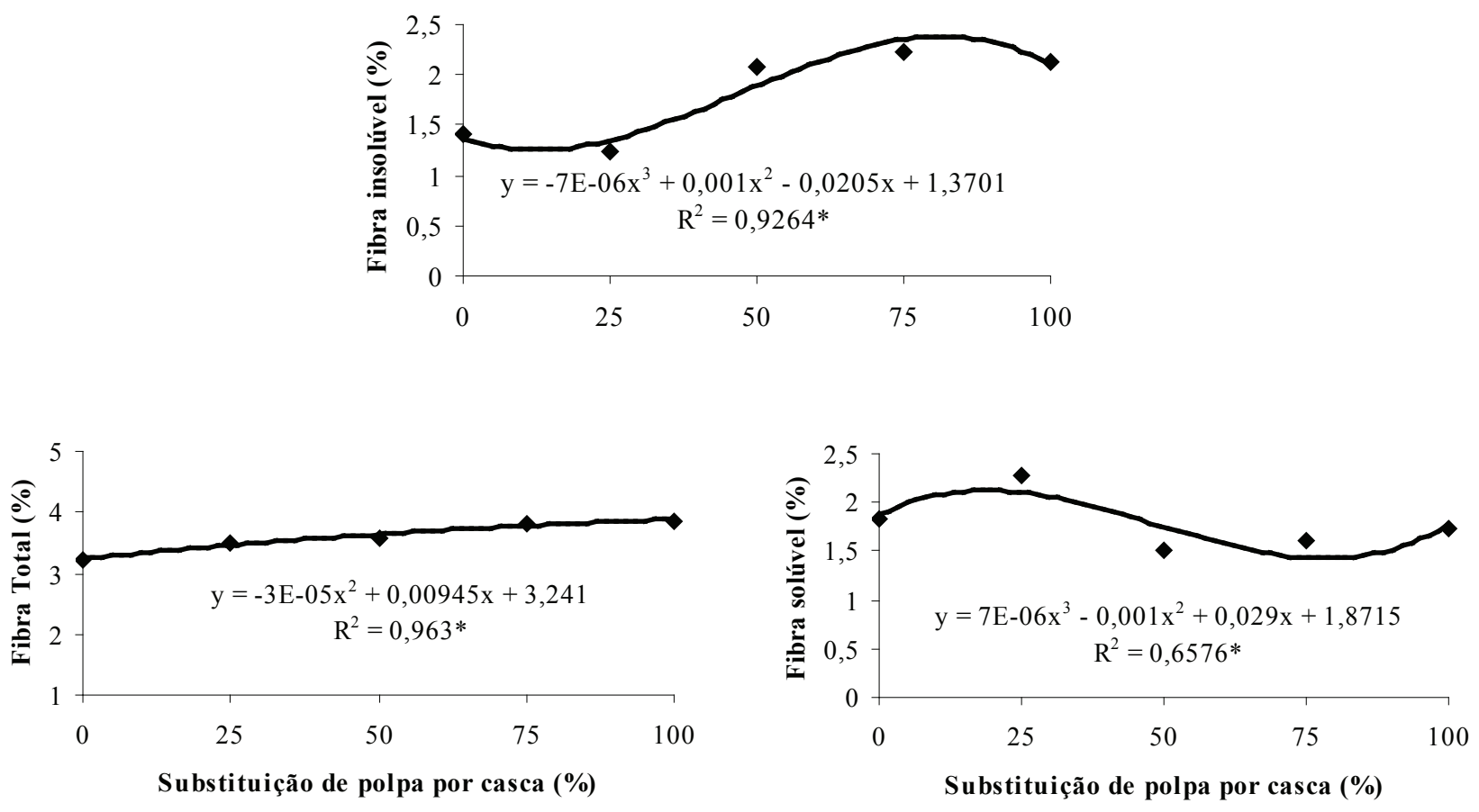

Figura 4. Quantificação das fibras totais, solúveis e insolúveis (\%) dos tratamentos com diferentes níveis de cascas de manga, em substituição à polpa (Goiânia, GO, 2009). * p $\leq 0,05$. 
a quantidade de fibras totais. Segundo Gonçalves (1998), a manga Haden apresenta teor de fibra total de $0,76 \%$. Gaínza (2001) encontrou $15,37 \%$ de fibra bruta na casca da manga, evidenciando o fato de os doces de casca de manga possuírem maior teor deste tipo de fibra.

Guerra et al. (2004) encontraram 3,34\% de fibra total, 2,08\% de fibra insolúvel e 1,26\% de fibra solúvel na manga. Ajila et al. (2007), estudando os componentes disponíveis nas cascas de mangas maduras (variedades indianas), encontraram teores de fibra bruta entre $5,8 \%$ e $7,4 \%$. O consumo de alimentos ricos em fibra alimentar solúvel é essencial para manter a saúde e reduzir os riscos de diversas doenças (Ajila et al. 2007).

Os teores de fibras solúveis variaram 1,5$2,27 \%$. Notou-se, também, que apenas o tratamento com $25 \%$ de casca diferiu, estatisticamente, dos demais. A característica da casca da manga é que esta tem um índice elevado de fibra dietética solúvel, que é relatada como fibra benéfica para a saúde (Ajila et al. 2007).

As fibras insolúveis compreendem os componentes da parede celular dos vegetais, como a celulose, hemicelulose e lignina, os quais não são digeridos pelo organismo humano, assumindo pa-
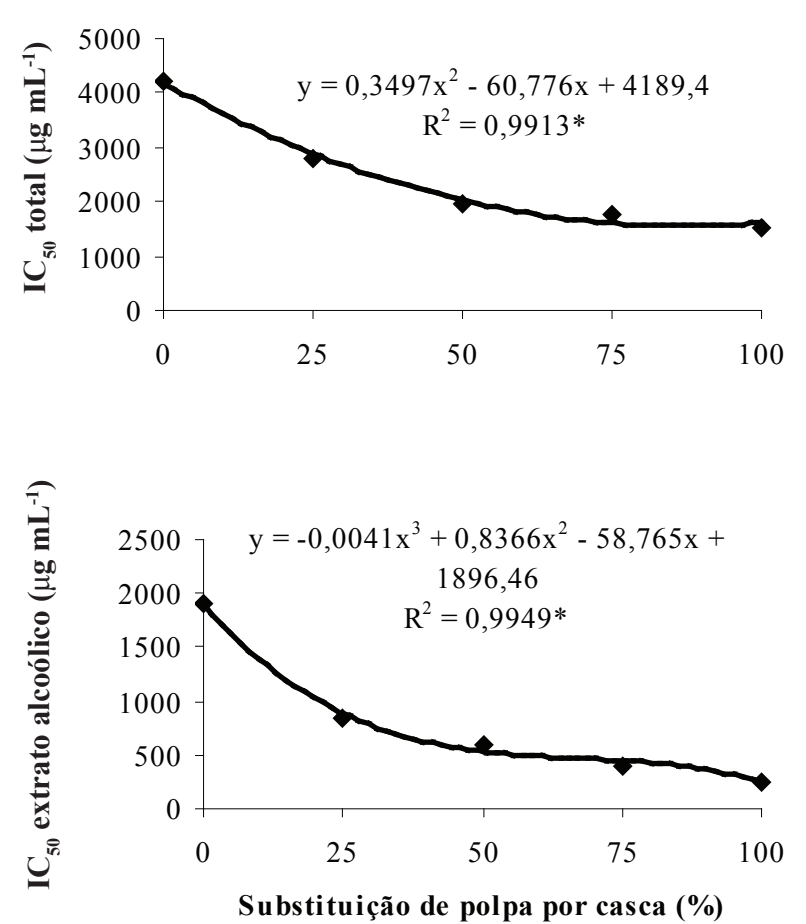

pel importantíssimo nos movimentos peristálticos e no aumento do bolo fecal, evitando a constipação e anulando o risco de surgimento de hemorróidas e diverticulites (Vilas Boas 1999).

Para que um produto seja considerado fonte de fibras alimentares, este deve conter um mínimo

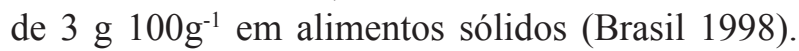
Logo, os produtos fabricados utilizando-se polpa e casca de manga podem ser classificados como fonte de fibras alimentares.

O potencial antioxidante total dos diferentes tratamentos de doce de casca de manga pode ser expresso como concentração final do extrato (etéreo, alcoólico e aquoso) necessário para reagir com o radical oxidante $\mathrm{DPPH}$, em 50\% $\left(\mathrm{IC}_{50}\right)$. Os resultados são apresentados na Figura 5. O grau de descoloração indica o potencial antioxidante do extrato. Um extrato que apresente alto potencial para sequestrar radicais livres possui baixo valor de $\mathrm{IC}_{50}$. Desta forma, uma pequena quantidade de extrato é capaz de proporcionar a diminuição da concentração inicial do radical DPPH em 50\%, ou seja, inibir a oxidação do radical em 50\% (Roesler et al. 2007).

Observou-se que, com a incorporação da casca de manga, houve decréscimo do $\mathrm{IC}_{50}$, ou seja, necessita-se de menos amostra para reagir com o
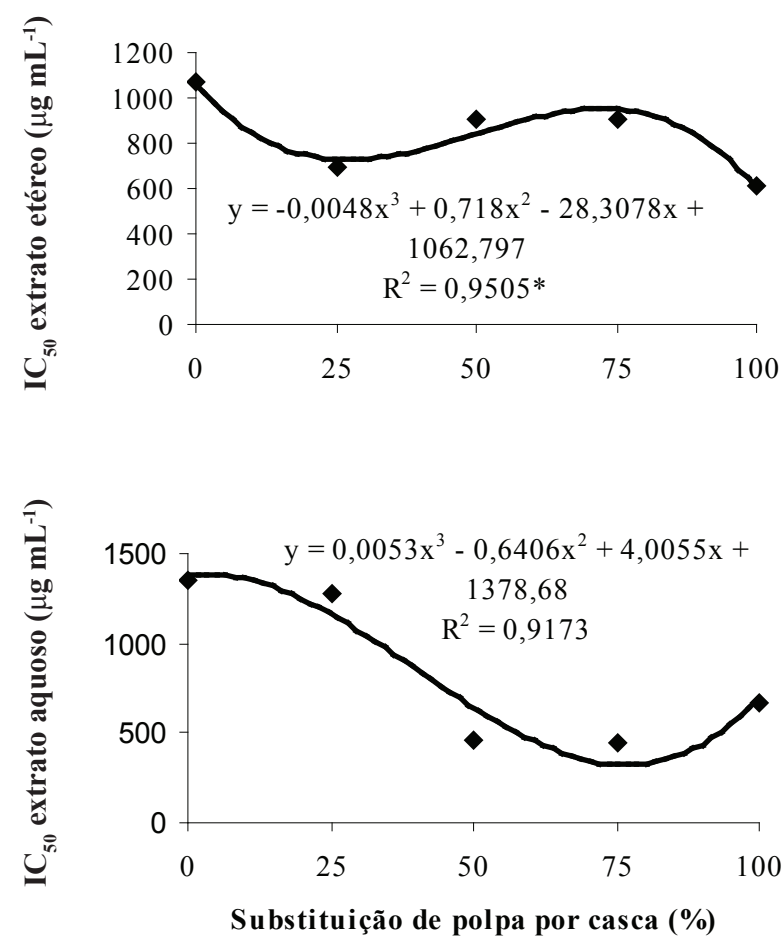

Figura 5. Determinação da capacidade de sequestrar radicais livres (DPPH), expressa em $\mathrm{IC}_{50}$, dos tratamentos com diferentes níveis de cascas de manga, em substituição à polpa (Goiânia, GO, 2009). * $\mathrm{p} \leq 0,05$. 
oxidante. Logo, pode-se presumir que as cascas possuem maior atividade antioxidante que a polpa da fruta pesquisada.

No extrato alcoólico, notou-se uma curva decrescente, na qual a variação foi de 258,5-1.907,66 $\mu \mathrm{g} \mathrm{mL} \mathrm{mL}^{-1}$ (Figura 5), evidenciando, novamente, o fato de que quando aumenta-se o teor de casca na formulação, aumenta-se, também, a atividade antioxidante.

No extrato aquoso, observou-se comportamento diferenciado dos demais, no qual a curva, inicialmente com valor de $1348,27 \mu \mathrm{g} \mathrm{mL}^{-1}$, decresceu com a incorporação de $25 \%$ de casca e aumentou na amostra com 100\% de casca (Figura 5).

No teste de aceitabilidade do doce de corte, dentre os recrutados, a faixa etária variou entre 6 e 89 anos. O maior percentual de consumidores encontrava-se na faixa etária entre 41 e 50 anos (22\%), seguido por aqueles entre 21 e 40 anos (18\%) e entre 51 e 60 anos (17\%). As médias dos atributos aparência, aroma, sabor e cor estão apresentadas na Figura 6.

Todos os atributos avaliados no teste de aceitabilidade (Figura 6) obtiveram escores entre seis (gostei ligeiramente) e nove (gostei extremamente). A aparência, o sabor e a cor, segundo a opinião dos consumidores goianienses, foram diferentes para todos os tratamentos, diferindo, estatisticamente, entre si.
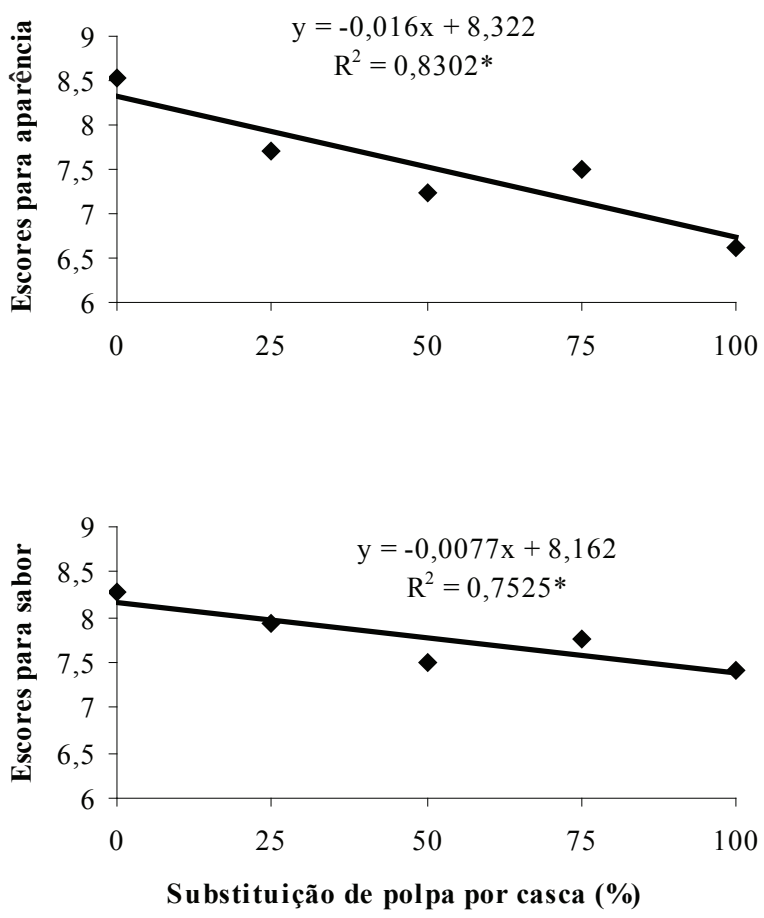

O tratamento formulado com $100 \%$ de casca (Figura 6) apresentou menor escore para o atributo aparência $(6,63)$, devido ao fato de este tratamento não ter adquirido consistência desejável para doce de corte, quando comparado aos demais tratamentos. É notável que os consumidores, em geral, avaliem determinado produto primeiramente pela sua aparência global. Conforme relatado por Konkel et al. (2004), muitas vezes, o atributo que se pretende avaliar é influenciado por outros fatores, como a quantidade de amostras e a cor do produto. Todavia, os tratamentos com $25 \%, 50 \%$ e $75 \%$ de casca na formulação (Figura 6) obtiveram escores superiores a sete, ou seja, "gostei moderadamente", na escala hedônica.

Santana \& Oliveira (2005), com o objetivo de aproveitar a casca de melancia (Curcubita citrullus Shrad), parte geralmente desprezada pelos consumidores, desenvolveram doces alternativos. Os resultados mostraram, também, que os doces cremosos e em calda, com e sem adição de coco, obtiveram excelente aceitabilidade entre os consumidores adultos e crianças.

Com relação às análises microbiológicas, os resultados foram satisfatórios para todos os tratamentos (ausência de coliformes a $35^{\circ} \mathrm{C}$ e $45^{\circ} \mathrm{C}$, de Salmonella e fungos filamentosos e de leveduras),
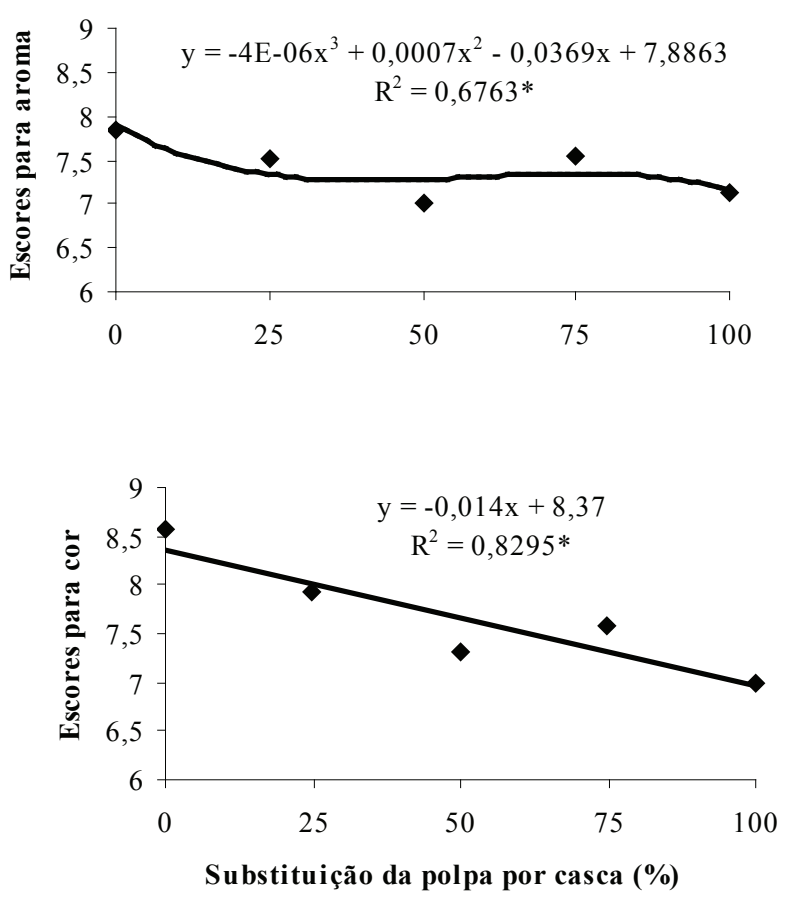

Figura 6. Escores dos atributos sensoriais analisados nos tratamentos com diferentes níveis de cascas de manga, em substituição à polpa (Goiânia, GO, 2009). * p $\leq 0,05$. 
enquadrando-se nos limites permitidos pela legislação brasileira (Brasil 2001). Os resultados sugerem que houve bons procedimentos no processamento dos doces, como sanificação adequada das frutas e dos equipamentos utilizados, além da efetividade dos métodos de conservação empregados.

\section{CONCLUSÕES}

1. A utilização de cascas de manga cv. Haden, em substituição parcial ou total à polpa, em doces de corte, foi viável, sob os aspectos nutricional, sensorial e microbiológico.

2. As cascas misturadas aos doces reduziram o valor calórico, porém, aumentaram os teores de fibras e a atividade antioxidante, elevando os valores nutricionais.

3. Ambos os tipos de doce desenvolvidos tiveram boa aceitabilidade entre os consumidores, estando dentro dos padrões microbiológicos estabelecidos pela legislação brasileira.

\section{AGRADECIMENTOS}

Ao Conselho Nacional de Desenvolvimento Científico e Tecnológico (CNPq), Coordenação de Aperfeiçoamento de Pessoal de Nível Superior (Capes) e Fundação de Amparo à Pesquisa do Estado de Minas Gerais

(Fapemig), pelo apoio financeiro.

\section{REFERÊNCIAS}

AJILA, C. M.; BHAT, S. G.; PRASADA RAO, U. J. S. Valuable components of raw and ripe peels from two Indian mango varieties. Food Chemistry, Washington, DC, v. 102, n. 4, p. 1006-1011, 2007.

ASSOCIATION OF OFFICIAL ANALYTICAL CHEMISTS (AOAC). Official methods of analysis of the Association of Official Analytical Chemists. Arlington: Helrich, 1997.

BLIGH, E. G.; DYER, W. J. A rapid method of total lipid extraction and purification. Canadian Journal of Biochemistry and Physiology, Ottawa, v. 37, n. 8, p. 911917, 1959.

BORGUINI, R. G.; TORRES, E. F. S. Tomatoes and tomato products as dietary sources of antioxidants. Food Reviews International, Philadelphia, v. 25, n. 4, p. 313325, 2009.
BRAND-WILLIAMS, W.; CUVELIER, M. E; BERSET, C. Use of a free radical method to evaluate antioxidant activity. Lebensmittel Wissenschaft Und Technologie, Zürich, v. 28, n. 1, p. 25-30, 1995.

BRASIL. Métodos físicoquímicos para análise de alimentos. 4. ed. Brasília, DF: Instituto Adolfo Lutz, 2005.

BRASIL. Ministério da Saúde. Portaria no 27 SVS/ MS, de 13 de janeiro de 1998 - ANVS. Regulamento técnico referente à informação nutricional complementar. Diário Oficial da República Federativa do Brasil, Poder Executivo, Brasília, DF, 16 jan. 1998. Seção 1, p. 11-E.

BRASIL. Ministério da Saúde. Resolução Normativa n ${ }^{\circ}$ 9, de 1978 - CNNPA. Define termos sobre doce em pasta. Diário Oficial da República Federativa do Brasil, Poder Executivo, Brasília, DF, 11 dez. 1978. Disponível em: $<$ http://www.anvisa.gov.br/legis/resol/09_78_doces.htm $>$. Acesso em: 15 jan. 2010.

BRASIL. Ministério da Saúde. Resolução RDC Anvisa/ $\mathrm{MS} \mathrm{n}^{\circ} 12$, de 02 de janeiro de 2001 - ANVS. Regulamento técnico sobre os padrões microbiológicos para alimentos. Diário Oficial da República Federativa do Brasil, Poder Executivo, Brasília, DF, 10 jan. 2001. Seção 1. Disponível em: <http://www.anvisa.gov.br/legis/resol/12_01rdc. htm>. Acesso em: jan. 2010.

DAMIANI, C. et al. Avaliação química de geleias de manga formuladas com diferentes níveis de cascas em substituição à polpa. Ciência e Agrotecnologia, Lavras, v. 31, n. 1, p. 177-184, jan./fev. 2009.

DELLA MODESTA, R. C. Manual de análise sensorial de alimentos e bebidas. Rio de Janeiro: Embrapa-CTAA, 1994.

DUBOIS, M. K. A. et al. Colorimetric method for determination of sugars and related substances. Analytical Chemistry, Columbus, v. 28, n. 3, p. 350-55, 1956.

FOOD AND AGRICULTURE ORGANIZATION OF THE UNITED NATIONS (FAO). A manga no mundo $e$ no Brasil. 2009. Disponível em: <https://www.fao.org. br>. Acesso em: 22 dez. 2009.

GAÍNZA, A. I. Evaluación y caracterización químicobromatologica de diferentes subproductos vegetales. Alimentaria, Madrid, n. 320, p.119-126, 2001.

GONÇALVES, N. B. Caracterização física e química dos frutos de cultivares de mangueira (Mangifera indica L.). Ciência e Agrotecnologia, Lavras, v. 22, n. 1, p. 72-78, 1998.

GUERRA, N. B. et al. Modificações do método gravimétrico não enzimático para determinar fibra alimentar solúvel e insolúvel em frutos. Revista Nutrição, Campinas, v. 17, n. 1, p. 45-52, 2004. 
KAUR, C.; KAPOOR, H. C. Anti-oxidant activity and total phenolic content of some Asian vegetables. International Journal of Food Science and Technology, Malden, v. 37, n. 2, p. 153-161, 2002.

KONKEL, F. E. et al. Avaliação sensorial de doce de leite pastoso com diferentes concentrações de amido. Ciência e Tecnologia de Alimentos, Campinas, v. 24, n. 2, p. 249254, 2004.

NASCIMENTO, R. M. F. et al. Características sensoriales, microbiológicas y fisico-químicas de dulces em masa de cáscara de maracujá amarillo. Alimentaria, Madrid, n. 347, p. 97-100, 2003.

OLIVEIRA, L. F. et al. Aproveitamento alternativo da casca do maracujá-amarelo (Passiflora edulis f. Flavicarpa) para produção de doce em calda. Ciência e Tecnologia de Alimentos, Campinas, v. 33, n. 3, p. 259-262, 2002.

OLIVEIRA, M. S. et al. Atividade antioxidante e antifúngica de extratos vegetais. Revista Alimentos e Nutrição, Araraquara, v. 18, n. 3, p. 267-275, 2007.

ROESLER, R. et al. Atividade antioxidante de frutos do Cerrado. Ciência e Tecnologia de Alimentos, Campinas, v. 27, n. 1, p. 53-60, 2007.

SANTANA, A. F.; OLIVEIRA, L. F. Aproveitamento da casca de melancia (Curcubita citrullus Shrad) na produção artesanal de doces alternativos. Revista Alimentos e Nutrição, Araraquara, v. 16, n. 4, p. 363-368, 2005.
SILVA, N.; JUNQUEIRA, V. C. A.; SILVEIRA, N. F. A. Manual de métodos de análise microbiológica de alimentos. São Paulo: Varela, 2007.

SILVA, R. A. et al. Avaliação físico-química e sensorial de néctares de manga de diferentes marcas comercializadas em Fortaleza/CE. Publicatio UEPG, Ponta Grossa, v. 11, n. 3, p. 21-26, 2005.

SOARES JÚNIOR, A. M.; MAIA, A. B. R. B.; NELSON, D. L. Estudo do efeito de algumas variáveis de fabricação no perfil texturométrico do doce de manga. Ciência e Tecnologia de Alimentos, Campinas, v. 23, n. 1, p. 76-80, 2003.

VILAS BOAS, E. V. B. Alimentos e nutrição. Lavras: UFLa, 1999.

WILSON, E. D.; SANTOS, A. C.; VIEIRA, E. C. Energia. In: DUTRA OLIVEIRA, J. E.; SANTOS, A. C.; WILSON, E. D. Nutrição básica. São Paulo: Savier, 1982. p. 79-97.

WOLFE, K. Antioxidant activity of apple peels. Journal of Agricultural Food Chemistry, Washington, DC, v. 51, n. 3, p. 609-614, 2003. 